\title{
Role of Routine Peritoneal Biopsies During Risk Reducing Salpingo-Oophorectomy (RRSO)
}

\section{Bedeutung der routinemäßigen Durchführung von peritonealen Biopsien bei risikoreduzierenden Salpingo-Oophorektomien (RRSO)}

\section{(c) 9 (9)}

Authors

Therese Pross $^{1 *}$, Maria Margarete Karsten ${ }^{1 *}$, Jens-Uwe Blohmer ${ }^{1}$, Dorothee Speiser ${ }^{1,2}$

\section{Affiliations}

1 Charité - Universitätsmedizin Berlin, Department of Gynecology and breast center, Berlin, Germany

2 Charité - Universitätsmedizin Berlin, Hereditary Breast and Ovarian Cancer Center, Berlin, Germany

\section{Key words}

hereditary ovarian cancer, risk-reducing surgery,

salpingo-oophorectomy, hereditary breast cancer, BRCA

\section{Schlüsselwörter}

erblicher Eierstockkrebs, risikoreduzierende Chirurgie, Salpingo-Oophorektomie, erblicher Brustkrebs, BRCA

\author{
received 15.1.2021 \\ accepted after revision $\quad$ 17.2.2021 \\ Bibliography \\ Geburtsh Frauenheilk 2021; 81: 1031-1038 \\ DOI 10.1055/a-1395-7715 \\ ISSN 0016-5751 \\ (c) 2021. The Author(s).
}

This is an open access article published by Thieme under the terms of the Creative Commons Attribution-NonDerivative-NonCommercial-License, permitting copying and reproduction so long as the original work is given appropriate credit. Contents may not be used for commercial purposes, or adapted, remixed, transformed or built upon. (https://creativecommons.org/licenses/by-nc-nd/4.0/)

Georg Thieme Verlag KG, Rüdigerstraße 14,

70469 Stuttgart, Germany

Correspondence

Dorothee Speiser, MD, PhD

Charité - Universitätsmedizin Berlin,

Department of Gynecology and Breast Center

Charitéplatz 1, 10117 Berlin, Germany

dorothee.speiser@charite.de

* These authors contributed equally.

\section{ABSTRACT}

Objective The objective of this retrospective study was to assess the role of routine peritoneal biopsies during risk reducing salpingo-oophorectomy (RRSO).

Methods Data of 204 women who underwent RRSO between January 1, 2014 and February 20, 2020 at Charité - Universitätsmedizin Berlin, Campus Mitte were retrospectively analyzed. RRSO was done according to the standard operating procedures of the German Consortium Hereditary Breast and Ovarian Cancer (GC-HBOC) with peritoneal washing and several peritoneal biopsies. Specimen collected during RRSO were analyzed using the protocol for Sectioning and Extensively Examining the FIMbria (SEE-FIM). Perioperative complications were classified using the Clavien-Dindo-Classification. Results 147 women who underwent RRSO had peritoneal biopsies and pelvic washing, 44 women had none of that. 123 patients (64.4\%) carried a pathologic variant in gBRCA1, 53 $(27.7 \%)$ carried a pathologic variant in gBRCA2. Histopathological evaluation identified four patients $(2.1 \%)$ with pathological findings. Neither peritoneal biopsies nor pelvic washings revealed additional information after histological examination. There was no statistically significant difference in complication rate between the two groups. The mean surgery time for RRSO without peritoneal biopsies was 64.3 minutes compared to 77.8 minutes with peritoneal biopsies. That shows a statistically significant prolongation of $16 \%$ (13.5 minutes, $p=0.0383$ ).

Conclusions The routine use of peritoneal biopsies during RRSO does not improve detection of occult ovarian cancer or STIC but prolongs the operation time significantly. By omitting peritoneal biopsies in RRSO not only perioperative risks are diminished but also costs could be reduced by shortening of surgery time as well as decreased number of pathological samples.

\section{ZUSAMMENFASSUNG}

Zielsetzung Ziel dieser retrospektiven Studie war es, die Bedeutung von routinemäßig durchgeführten peritonealen Biopsien bei risikoreduzierenden Salpingo-Oophorektomien (RRSO) zu evaluieren. 
Methoden Die Daten von 204 Frauen, die sich zwischen dem 1. Januar 2014 und dem 20. Februar 2020 an der Charité Universitätsmedizin Berlin, Campus Mitte, einer RRSO unterzogen, wurden retrospektiv analysiert. Die RRSO-Eingriffe wurden entsprechend den Vorgaben des Deutschen Konsortiums Familiärer Brust- und Eierstockkrebs zusammen mit Peritoneallavagen und mehreren peritonealen Biopsien durchgeführt. Die entnommenen Proben wurde gemäß dem SEE-FIM-Protokoll (SEE-FIM: Sectioning and Extensively Examining the FIMbria) analysiert. Perioperative Komplikationen wurden mithilfe der Clavien-Dindo-Klassifikation erfasst.

Ergebnisse Bei 147 Frauen, die sich einer RRSO unterzogen, wurden peritoneale Biopsien entnommen bzw. eine Peritonealspülung durchgeführt. Bei 44 Frauen wurde nur eine RSSO durchgeführt. Bei 123 Patientinnen (64,4\%) fand sich eine pathologische gBRCA1-Mutation, 53 (27,7\%) hatten eine pathologische gBRCA2-Mutation. Bei der histopathologischen Untersuchung wurden pathologische Befunde bei 4 Patientinnen
$(2,1 \%)$ festgestellt. Weder peritoneale Biopsien noch Bauchspülungen führten nach der histologischen Untersuchung zu weiteren Befunden. Es gab keinen statistisch signifikanten Unterschied zwischen beiden Gruppen in Bezug auf die Komplikationsraten. Die durchschnittliche Operationszeit für eine RRSO ohne peritoneale Biopsie betrug 64,3 Minuten verglichen mit 77,8 Minuten für eine RSSO mit peritonealer Biopsie. Das kam einer statistisch signifikanten Verlängerung der Operationszeit von $16 \%$ gleich (13,5 Minuten, $\mathrm{p}=0,0383$ ).

Schlussfolgerungen Die routinemäßige Durchführung von peritonealen Biopsien während einer RRSO führt nicht zu einer besseren Eierstockkrebs- oder STIC-Erkennungsrate, sondern nur zu einer signifikanten Verlängerung der Operationszeit. Werden keine peritoneale Biopsien bei der RSSO durchgeführt, verringern sich nicht nur die perioperativen Risiken, sondern auch die Kosten, da sich die Operationszeit verkürzt und die Anzahl der zur untersuchenden Proben verringert.

\section{Objective}

One third of all malignant neoplasms of the female genitals and half of all deaths from cancer are attributable to ovarian cancer (OC). The lifetime risk of $O C$ is about 1 in 75 (cumulative risk to age 80 of $1.3-1.5 \%$ ) [1]. Due to the fact that $O C$ is mainly diagnosed only at an advanced stage (76\% stage III/IV), 5-year survival rates are currently only $43 \%[2,3]$. Among carriers of a pathogenic germline BRCA1-mutation ( $g B R C A 1)$ cumulative lifetime risks are estimated at 44-49\%, gBRCA2-mutations carriers' lifetime risks ranging between 17 to $21 \%[1,4]$. Mutations in genes like PALB2, RAD51C/D, BRIP1 and the Hereditary Non-Polyposis Coli (HNPCC) genes (MLH1, MSH2, MSH6, PMS2) are responsible for less than $5 \%$ of the hereditary ovarian cancer but probably predispose to a lifetime risk of at least 5-11\% [1].

Due to ineffective screening programs for OC, risk reducing bilateral salpingo-oophorectomy (RRSO) is suggested for $g B R C A 1 / 2$ mutation carriers [3].The goal is to undergo RRSO as late as possible to reduce side effects caused by iatrogenic menopause and premature ovarian failure (POF) but early enough to prevent OC. At the moment, according to international guidelines RRSO is recommended between the age of 35 and 40 for gBRCA1 mutation carriers and between the age of 40 and 45 for gBRCA2 mutation carriers but at least 5 years before the first diagnosis of $O C$ in the family occurred $[3,5]$. These recommendations are based on individual risk calculation with the Breast and Ovarian Analysis of Disease Incidence and Carrier Estimation Algorithm (BOADICEA), a validated calculation program for cancer risks [6, 7].

There have been numerous case series and a few prospective studies evaluating and demonstrating the efficacy of RRSO in reducing the risk for OC up to $95 \%[8,9]$. Even though big clinical trials are missing, RRSO has become the most important OC preventive strategy for $g B R C A 1 / 2$ mutation carriers [8]. Although RRSO is an OC preventive strategy, occult malignancies are diagnosed at the time of surgery in $2-17 \%$ of all cases dependent on age and mutation status $[3,8]$. The wide range might be explica- ble through different study populations especially in age and mutation spectrum. Furthermore, different intraoperative and pathological protocols add to variations in study outcome $[3,10]$. It is already known that BRCA1 carriers have the highest risk of occult neoplasia at RRSO and that the frequency of incidental discoveries increases with age [11].

Following the detection of precursor intraepithelial lesions in the fallopian tubes, clinicians and pathologists concluded that high grade serous $\mathrm{OC}$ originates from the fallopian tube rather than from the ovary (serous tubal intraepithelial carcinoma = STIC) $[12,13]$. Therefore, risk reducing salpingectomy with delayed oophorectomy (RSDO) has been suggested as an alternative to RRSO to avoid surgical menopause and to maintain fertility. Clinical trials proving the efficacy of RSDO are under way, first data seem promising $[8,14,15]$.

Although there is clear evidence for the efficacy of RRSO and the procedure is implemented in most hospitals, the extent of the surgery remains debatable [8]. In most of the published studies regarding RRSO, there is insufficient information about standardized surgical protocols. There are several studies evaluating pelvic washings in RRSO to identify atypical cells suggesting possible malignancy. Because atypical cells can be detected in 1 to $5 \%$ [8], they are routinely recommended for RRSO. However, only a few of the women with atypical cells in pelvic washings develop carcinoma on the long run. Not only the clinical relevance of positive pelvic washings but also therapeutic consequences such as chemotherapy therefore remain unclear $[9,10]$. To date, there is no proof for the benefit of peritoneal washings nor peritoneal biopsies in the context of RRSO.

In general, laparoscopic salpingo-oophorectomy has a low perioperative complication rate and is therefore considered a safe procedure [16]. There are only two published studies looking at the general complication rate and type of complications in RRSO, but not a single study relating complications to peritoneal biopsies. 
The effect and risks of peritoneal biopsies in RRSO therefore remain unclear. Currently, peritoneal biopsies are part of the standard operating procedures (SOP) of the German Consortium Hereditary Breast and Ovarian Cancer (GC-HBOC) and are therefore taken in RRSO routinely. To our knowledge, this is the first study to evaluate the effect of peritoneal biopsies in RRSO in relation to possible side effects.

Our study aimed at:

1. the question if routine peritoneal biopsies in women undergoing RRSO provide any additional information and therefore offer an additional oncological benefit,

2. the comparison of the duration of surgeries between patients undergoing RRSO with and without additional peritoneal biopsies,

3. the evaluation of perioperative complication rate as well as comparison of complications of women undergoing RRSO with and without additional peritoneal biopsies.

\section{Methods}

We included 204 patients in this retrospective study. Patients underwent RRSO between January 1, 2014 and February 20, 2020 at Charité Universitätsmedizin Berlin, Campus Mitte after genetic counseling and testing. Patient data as well as clinical and pathological information were extracted from the electronic patient file and subsequently anonymized.

\section{RRSO}

According to the standard operating procedures of the GC HBOC for RRSO introduced in 2015 we did peritoneal washings at the beginning of laparoscopy and routine peritoneal biopsies at each of the following sites: paracolic gutters left and right, ovarian fossa left and right, pouch of Douglas and the peritoneal fold of the prevesical pouch. Patients are positioned flat on their back head down for RRSO in our institution. As university hospital, we have an active training program for residents in oncologic surgery. Each procedure performed by a resident in training as a teaching case was supervised by a surgeon experienced in oncologic surgery. We therefore divided the total of 31 surgeons into three different levels of expertise in order to avoid distortion of the duration of surgeries. We also analyzed the differences in operation time between those three levels of expertise.

To classify perioperative complications, we used the ClavienDindo-Classification, in which any deviation from the normal postoperative course without need for pharmacological treatment or with need for surgical, endoscopic and radiological interventions is ranked according to the needed intervention (Grade I-V) [17, 18].

\section{Pathological analysis}

All specimen collected during RRSO were analyzed using the protocol for Sectioning and Extensively Examining the FIMbria (SEE-FIM) [19] at the Institute of Pathology of Charité - Universitätsmedizin Berlin by experienced pathologists trained in gynecologic pathology. Ovarian cancer detected as occult cancer during RRSO was staged following the latest classification by the International Federation of Gynecology and Obstetrics (FIGO).

\section{Statistical analysis}

Whereas frequencies and proportions were used as summary statistics for categorical variables, mean (standard deviation) and medians (interquartile range [IQR]) were used for the continuous variables. Regression analysis was done after logarithmizing the operating time. All calculated p-values were two-sided, and values $<0.05$ were considered statistically significant. All calculations were done with IBM SPSS Statistics.

\section{Results}

A total of 204 women underwent RRSO between January 1, 2014 and February 20, 2020 at the Department of Gynecology and Breast Center, Charité - Universitätsmedizin Berlin, following extensive counseling. Thirteen patients, in which RRSO was combined with any other operation (i.e. enucleation of myoma, mastectomy, hysteroscopy) have been excluded from the analysis. Of the remaining 191 women, 147 had peritoneal biopsies and pelvic washings, 44 women underwent RRSO without washings or further biopsies. All procedures where performed laparoscopically. The mean age at time of RRSO was $48.3 \pm 9.1$ years. 102 of 191 patients (53.4\%) had a history of breast cancer, of those 84 had unilateral and 18 had bilateral 84 had unilateral disease. The median hospital stay after RRSO was 2.6 days, ranging from 1 to 5 days. The two groups (with vs. without peritoneal biopsies) did not differ significantly in any of the above-mentioned characteristics. Descriptive statistic is shown in $>$ Table 1.

\section{Mutation status}

123 patients $(64,4 \%)$ carried a pathological gBRCA1 mutation and $53(27,7 \%)$ carried a pathological gBRCA2 mutation ( $\triangleright$ Table 2 ). One patient had a pathogenic variant in one of the HNPCC genes (MSH1), another patient had a pathogenic variant in PALB2. Eight of 191 patients (4.2\%) did not want the pathogenic variant to appear in the clinic information system according to the German Gendiagnostikgesetz and can therefore not be classified. Five patients underwent RRSO without pathogenic variant, but with a severe family history of ovarian cancer.

\section{Histopathological evaluation}

Histopathological evaluation identified STIC lesions and OC in two patients and singular STIC lesion in one patient ( $\bullet$ Table 3 ). The fourth patient had an OC-like unifocal glandular proliferation in the ovarian cortex, which was too small $(<1 \mathrm{~mm})$ to give a definite classification regarding invasiveness. Therefore, it was classified as ovarian cancer. Three of the patients are participating in an annual follow-up at our hospital without any signs of recurrence until now. Follow-up information could not be found for one patient.

In none of the patients with a diagnosis of STIC and/or OC pelvic washing and peritoneal biopsies showed any signs of malignancy, nor did peritoneal biopsies and pelvic washings reveal any additional information in any other of the 144 women undergoing RRSO. For further surgical treatment of the four patients with malignant findings, see $>$ Table 3. 
- Table 1 Characteristics of women who underwent RRSO $(n=191)$.

\begin{tabular}{|c|c|c|c|}
\hline & $\begin{array}{l}\text { With biopsies } \\
n=147(100 \%)\end{array}$ & $\begin{array}{l}\text { Without biopsies } \\
n=44(100 \%)\end{array}$ & $\begin{array}{l}\text { Total } \\
n=191(100 \%)\end{array}$ \\
\hline & No. of patients (\%) & No. of patients (\%) & No. of patients (\%) \\
\hline \multicolumn{4}{|c|}{ Age at RRSO, years } \\
\hline Mean (SD) & $48.97(9.75)$ & $46.19(6.62)$ & $48.34(9.19)$ \\
\hline Median (IQR) & $48(41 ; 56)$ & $45(41 ; 51)$ & $48(41 ; 54.8)$ \\
\hline Range & $31 ; 77$ & $37 ; 65$ & $31 ; 77$ \\
\hline \multicolumn{4}{|c|}{ Prior breast cancer } \\
\hline None & $68(46.3)$ & $21(47.7)$ & $89(46.6)$ \\
\hline Unilateral & $66(44.9)$ & $18(40.9)$ & $84(44)$ \\
\hline Bilateral & $13(8.8)$ & $5(11.4)$ & $18(9.4)$ \\
\hline \multicolumn{4}{|c|}{ Length of stay in hospital } \\
\hline Mean (range) & $2.62(1 ; 5)$ & $2.79(2 ; 5)$ & $2.66(1 ; 5)$ \\
\hline \multicolumn{4}{|c|}{ Pathologic findings at RRSO } \\
\hline Benign & $144(98)$ & $43(97.7)$ & 187 (97.9) \\
\hline OC & $3(1.5)$ & $0(0)$ & $3(1.6)$ \\
\hline STIC & $1(0.5)$ & $1(2.3)$ & $2(1)$ \\
\hline \multicolumn{4}{|c|}{ Duration of operation ( $\mathrm{min}$ ) } \\
\hline Mean (SD) & $77.8(30.14)$ & $64.3(27.08)$ & $74.7(29.94)$ \\
\hline Median (IQR) & $72(55 ; 98.2)$ & $60(45.5 ; 83)$ & $69(53 ; 96)$ \\
\hline Range & $17 ; 173$ & $22 ; 129$ & $18 ; 173$ \\
\hline \multicolumn{4}{|c|}{ Expertise of the surgeon (Level 1 = resident in training, Level 2 = specialist in gynecology, Level 3 = certified oncogynecologist surgeon) } \\
\hline Level 1 & $43(29.2)$ & $11(25)$ & $54(28.3)$ \\
\hline Level 2 & $77(52.4)$ & $17(38.6)$ & $94(49.2)$ \\
\hline Level 3 & $27(18.4)$ & $16(36.4)$ & $43(22.5)$ \\
\hline \multicolumn{4}{|c|}{ Perioperative complications } \\
\hline Yes & $6(4.1)$ & $2(4.5)$ & $8(4.2)$ \\
\hline No & 141 (95.9) & $42(95.5)$ & $182(95.8)$ \\
\hline
\end{tabular}

- Table 2 Mutation status of women undergoing RRSO $(n=191)$.

\begin{tabular}{|l|l|l|l|}
\hline & With biopsies & Without biopsies & Total \\
$\mathbf{n = 1 4 7}(\mathbf{1 0 0})$ & $\mathbf{n = 4 4 ( 1 0 0 \% )}$ & $\mathbf{n}=\mathbf{1 9 1}(\mathbf{1 0 0 \% )}$ \\
\hline Mutation & $\mathbf{n}(\%)$ & $\mathbf{n}(\%)$ & $123(64,4)$ \\
\hline BRCA1 & $98(66,7)$ & $25(56,8)$ & $53(27,7)$ \\
\hline BRCA2 & $42(28,6)$ & $11(25)$ & $1(0,5)$ \\
\hline HNPCC & $0(0)$ & $1(2,3)$ & $1(0,5)$ \\
\hline PALB2 & $1(0,7)$ & $0(0)$ & $8(4,2)$ \\
\hline Not specified & $1(0,7)$ & $7(15,9)$ & $5(2,6)$ \\
\hline None & $5(3,4)$ & $0(0)$ & \\
\hline
\end{tabular}

\section{Duration of surgery}

The mean duration of surgery in RRSO without peritoneal biopsies was 64.3 minutes, in RRSO with peritoneal biopsies 77.8 minutes ( $\triangleright$ Table 1). Therefore, the difference in surgery time through peritoneal biopsies was 13.5 minutes (16\%) longer on average. This prolongation was statistically significant $(p=0.0383$, $>$ Table
4). As shown in $>$ Table 4, there was no difference in surgery time between a trained surgeon and a resident in training $(p=0.3644$, experience 2 vs. 1), but between an expert in oncologic surgery and a resident in training ( $p=0.0383$, experience 3 vs. 1$)$. 
- Table 3 Characteristics of patients with occult carcinoma and STIC at RRSO $(n=4 ; 2.1 \%)$.

\begin{tabular}{|c|c|c|c|c|c|c|c|}
\hline Age & Mutation & $\begin{array}{l}\text { Ovarian } \\
\text { pathology }\end{array}$ & $\begin{array}{l}\text { Fallopian } \\
\text { tube } \\
\text { pathology }\end{array}$ & $\begin{array}{l}\text { Pelvic } \\
\text { washing }\end{array}$ & $\begin{array}{l}\text { Peritoneal } \\
\text { biopsies }\end{array}$ & TNM/FIGO & Further surgical treatment \\
\hline 46 & BRCA2 & None & STIC & Not done & Not done & None & Peritoneal biopsies, appendectomy \\
\hline 48 & $B R C A 2$ & OC & STIC & Benign & Benign & $\begin{array}{l}\text { PT1b pN0 } \\
\text { G3 RO LO V0 } \\
\text { FIGO IB }\end{array}$ & $\begin{array}{l}\text { Staging surgery including hysterec- } \\
\text { tomy, omentectomy, pelvic and } \\
\text { paraaortic lymph node dissection, } \\
\text { peritoneal biopsies }\end{array}$ \\
\hline 64 & BRCA1 & OC & STIC & Benign & Benign & $\begin{array}{l}\text { PT3a pN0 } \\
\text { G3 RO LO V0 } \\
\text { FIGO IIIA }\end{array}$ & $\begin{array}{l}\text { Staging surgery including hysterec- } \\
\text { tomy, omentectomy, pelvic and } \\
\text { paraaortic lymph node dissection, } \\
\text { peritoneal biopsies }\end{array}$ \\
\hline 57 & BRCA1 & OC & None & Benign & Benign & $\begin{array}{l}\text { Unifocal glandu- } \\
\text { lar proliferation }\end{array}$ & Peritoneal biopsies \\
\hline
\end{tabular}

- Table 4 Statistical analysis of surgery time.

\begin{tabular}{|c|c|c|c|c|c|c|c|c|c|}
\hline & \multirow[b]{2}{*}{ Estimate } & \multirow[b]{2}{*}{$\begin{array}{l}\text { Std. } \\
\text { error }\end{array}$} & \multicolumn{2}{|c|}{$95 \%$ Confidence interval } & \multirow[b]{2}{*}{$\begin{array}{l}\text { Exp } \\
\text { (estimate) }\end{array}$} & \multicolumn{2}{|c|}{$95 \%$ Confidence interval } & \multirow[b]{2}{*}{$t$ value } & \multirow[b]{2}{*}{$\mathrm{p}$ value } \\
\hline & & & Lower & Upper & & Lower & Upper & & \\
\hline (Intercept) & 4.14 & 0.08 & 3.99 & 4.3 & - & - & - & 52.806 & $<0.0001$ \\
\hline Level 2 (vs. 1) & 0.06 & 0.07 & -0.07 & 0.2 & 1.06 & 0.93 & 1.22 & 0.909 & 0.3644 \\
\hline Level 3 (vs. 1) & -0.24 & 0.08 & -0.41 & -0.08 & 0.79 & 0.66 & 0.92 & -2.94 & $0.0037^{*}$ \\
\hline $\begin{array}{l}\text { Biopsy } \\
\text { yes (vs. no) }\end{array}$ & 0.15 & 0.07 & 0.01 & 0.29 & 1.16 & 1.01 & 1.34 & 2.087 & $0.0383^{*}$ \\
\hline R-squared & $\begin{array}{l}\text { adj. R- } \\
\text { squared }\end{array}$ & $\begin{array}{l}\text { F-sta- } \\
\text { tistic }\end{array}$ & nom DF & denom DF & $\mathrm{p}$ value & $n(\%)$ & & & \\
\hline 0.12 & 0.11 & 8.363 & 3 & 183 & 0 & $\begin{array}{l}187 \\
(98.4)\end{array}$ & & & \\
\hline
\end{tabular}

\section{Complication rate}

Using the Clavien-Dindo classification $[17,18]$ we found eight complications among 191 patients ( $\triangleright$ Table 1 ); six of them $(4.1 \%)$ in patients with additional peritoneal biopsies and two $(4.5 \%)$ in patients without peritoneal biopsies $(p=1.0)$. Complications are listed in $>$ Table 5. One woman had to undergo a second laparoscopy because of a prolapsing appendix epiploica after removing the drainage on the second postoperative day (the drainage was placed due to prolonged rinsing during surgery). One patient who underwent RRSO with peritoneal biopsies had a bladder lesion, probably due to thermal damage. Re-presentation four days after surgery for increasing lower abdominal pain revealed massive intraabdominal free fluid. We therefore performed a second laparoscopy, in which the fluid was confirmed to be urine and the bladder lesion was identified. We performed suturing of the lesion and the patient received a suprapubic urinary catheter for ten days. Over the years, three patients complained about post-
- Table 5 Classification of perioperative complications according to Clavien-Dindo classification $[17,18]$.

\begin{tabular}{|l|l|l|}
$\begin{array}{l}\text { Clavien- } \\
\text { Dindo } \\
\text { classification }\end{array}$ & $\begin{array}{l}\text { RRSO with } \\
\text { peritoneal biopsies } \\
\mathbf{n = 7}\end{array}$ & $\begin{array}{l}\text { RRSO without } \\
\text { peritoneal biopsies } \\
\mathbf{n = 2}\end{array}$ \\
\hline $\mathbf{I}$ & $\begin{array}{l}2 \times \text { hydronephrosis } \\
1 \text { st degree }\end{array}$ & \\
\hline II & Meralgia paraesthetica & \\
\hline IIIb & Bladder lesion with need & $\begin{array}{l}\text { Re-LSK } 2 \text { nd POD, prolapse } \\
\text { of Re-LSK }\end{array}$ \\
\hline & & \begin{tabular}{l} 
removing the drainage \\
\hline
\end{tabular} \\
\hline
\end{tabular}

operative meralgia paraesthetica. All of them could be treated conservatively with physiotherapy until symptoms were resolved. 


\section{Discussion}

Due to missing valid screening methods for ovarian cancer, mutation carriers with high risk of developing ovarian cancer are recommended to undergo RRSO. Several aspects of RRSO were analyzed in 197 patients who had surgery at the Department of Gynecology and Breast Center, Charité - Universitätsmedizin Berlin between 2014 and 2020.

Occult pathologic findings in RRSO occurred in $2.1 \%$ (1.6\% OC, STIC 1\%) among our patients. In comparison to the published data this rate of occult pathologic findings corresponds to the lower end of the range (2-17\%). Rudaitis et al. [3] detected an overall incidence of $15.5 \%$ in their study group (9.85\% STICs and $5.6 \%$ invasive $\mathrm{OC}$ ). They attributed the higher percentage mainly to the detailed pathologic examination within their prospective study. It also needs to be mentioned that their pathologic findings were all in women with pathogenic variants in BRCA1. Minig et al. [10] diagnosed STIC in $0.8 \%$ and simultaneous STIC and OC in $1.7 \%$. They also noticed a statistically significant higher risk for BRCA1 mutation carriers for the detection of occult neoplasia in RRSO. Powell et al. [20] detected seven malignancies (10.4\%) in 67 patients, five of them with a BRCA1 mutation. In contrast to the literature, only two of our four patients with pathologic findings had a $B R C A 1$ mutation, the other two were BRCA2 mutation carriers. The wide range of pathologic findings might be explained due to insufficient sectioning of the fallopian tubes by not following the SEE-FIM protocol [19], but also due to different inclusion criteria or small study groups.

We have found only two studies dealing with the subject of peritoneal biopsies in RRSO. Powell et al. [20] included biopsies of the pelvic and paracolic gutter peritoneum and omentum as well as pelvic washing in the study of 67 patients undergoing RRSO. They detected occult malignancies in $10.4 \%$, but none of the biopsies were abnormal. The authors were unable to draw any firm conclusions regarding their clinical utility. Miller et al. [8] included 70 women undergoing RRSO who had pelvic washings, omental biopsy, peritoneal biopsies of the bilateral paracolic gutters, anterior and posterior cul-de-sacs, and rectosigmoid in addition to RRSO. All omental and peritoneal biopsies examined were benign, even though they diagnosed STIC in $4.3 \%$ of the women. Therefore, they concluded that the routine use of omental and peritoneal biopsies for women undergoing RRSO does not improve the detection of occult malignancy. In our study, none of the peritoneal biopsies or washings showed signs of neoplasia. Even patients with occult neoplasia had benign pelvic washing and peritoneal biopsies. No atypical cells were detected. These findings are in line with others studies focusing on peritoneal biopsies in women undergoing RRSO (Miller et al. [8] and Powell et al. $[21,22])$. There are probably several reasons for the limited significance of peritoneal biopsies. First, the prevalence of primary peritoneal cancer is very low and therefore reduces the utility of peritoneal biopsies. Second, the amount of peritoneal tissue is very little compared to the whole peritoneal cavity. Even if you take biopsies from all recommended sites (paracolic gutters left and right, ovarian fossa left and right, pouch of Douglas and the peritoneal fold of the prevesical pouch), it will still be less than $1 \%$ of the peritoneum [8]. Furthermore, Piedimonte et al. [23] mentioned recent data in colorectal cancer indicating seeding of metastases through disseminated cancer cells while the carcinoma is still undetectable (less than $0.01 \mathrm{~m}^{3}$ ). Therefore, as shown in our study, the routine sampling of peritoneal biopsies during RRSO does not appear to provide any additional information or additional oncological benefit.

Although in our study there was no atypical pelvic washing, there are studies indicating additional benefit of pelvic washings in women undergoing RRSO. Medeiros et al. [24] reported one positive pelvic washing in a woman negative for OC and STIC in routine pathological examination among 26 operations. Therefore, they did additional immunohistochemistry, which revealed a p53 and ki67 positive intraepithelial carcinoma in histological review. In the study of Minig et al. [10] one woman with positive pelvic washing underwent surgical staging including hysterectomy, omentectomy and lymphonodectomy without any proof of disease or further treatment. Until today, there is no standardized clinical management for patients with isolated positive pelvic washing or isolated STIC. Therefore, like most of the other authors we do not see an additional benefit in pelvic washings for now [4]. Further prospective studies need to evaluate the concept of pelvic washings and clinical consequences properly.

In general, laparoscopic salpingo-oophorectomy is accompanied by a low perioperative complication rate and therefore considered a safe and efficient procedure [16]. We only identified three studies looking at the complication rate and type of complications in RRSO. Kenkhuis et al. [9] described an intraoperative complication rate of $1.3 \%$ in 154 women undergoing laparoscopic RRSO. Conversion to laparotomy occurred at a rate of $0.6 \%$, and the postoperative complication rate was $3.1 \%$ [9,25]. Zakhour et al. [4] described a complication rate of $7.4 \%$ according to the Clavien-Dindo classification. $53 \%$ of those complications were postoperative fevers which did not require any intervention. One bowel and three bladder injuries occurred in patients undergoing concurrent hysterectomy. There is no consideration of additional peritoneal biopsies during RRSO. Only Rudaitis et al. [3] analyzed the additional risk of peritoneal biopsies during RRSO and state that laparoscopic RRSO with peritoneal staging is safe, without complications ( $0 \%$ ) observed in their series of 85 patients. In our study, there was no statistical difference between complication rate in patients undergoing RRSO with $(4.1 \%)$ or without $(4.5 \%)$ peritoneal biopsy. A complication rate of $4.1-4.5 \%$ is midrange compared to the literature, but higher than we expected. However, the nature of complications in our study leads to the assumption that a prolonged duration of surgery may lead to increased nerve irritation through positioning of patient or trocars. In addition, the removal of peritoneal biopsies close to the bladder or bowel and the use of bipolar current increases the risk of postoperative necrosis which could explain the postoperative bladder lesion with aggregation of urine in the abdominal cavity. Because the complication rate of RRSO in general is very low, further studies with larger study groups need to be done to evaluate the additional risk of peritoneal biopsies.

In our study, surgery time was significantly extended by $16 \%$ (13.5 minutes) due to the performance of peritoneal biopsies. As university hospital, we have a high number of residents in training over the years. To avoid distortion of surgery time, we divided the 
total of our 31 surgeons into three different levels of expertise. There was no significant difference in surgery time between residents in training and trained surgeons, but between residents in training and experts (surgeons certified in gynecologic oncology). The difference between RRSO with or without peritoneal biopsies stayed significant, nevertheless. Different surgical expertise could be one explanation why the average duration of RRSO with peritoneal biopsies $(77.8 \mathrm{~min})$ and without peritoneal biopsies (64.3 min) was longer than mentioned in the study of Rudaitis et al. [3] $(43 \mathrm{~min} ; 25,65)$ but shorter than mentioned by Nebgen et al. [15] (136 min). All other studies do not mention the duration of surgery without peritoneal biopsies or any statistical comparison. Unfortunately, no other study measured the duration of surgery. In the future, this aspect for time saving in the interest of our patients should be addressed in combination with other aspects like patient turnover time.

\section{Conclusion}

Occult pathologic findings in RRSO occurred in 2.1\% (1.6\% OC, STIC 1\%) among our patients. In comparison to the published data this rate of occult pathologic findings corresponds to the lower end of the range $(2-17 \%)$. The routine use of peritoneal biopsies in patients undergoing RRSO does not improve the detection of occult ovarian cancer or STIC but prolongs the operation time significantly. There was no significant difference in surgery time between residents in training and trained surgeons, but between residents in training and experts (surgeons certified in gynecologic oncology). The complication rate in our study in patients with and without peritoneal biopsies did not differ significantly. However, the nature of complications led to a more conscientious intraoperative positioning of patient and trocars in our institution.

By omitting peritoneal biopsies in RRSO not only perioperative risks might be diminished but also costs could be reduced by shortening the duration of surgery time and as well as decreasing the number of pathological samples. Further prospective studies are needed to evaluate this in a larger group of patients.

\section{Declarations}

\section{Funding}

This research did not receive any specific grant from funding agencies in the public, commercial, or not-for-profit sectors.

\section{Availability of data and material}

Available upon personal request at corresponding author.

\section{Code availability}

Not applicable.

\section{Ethical approval}

Not applicable for retrospective data analysis according to internal protocol.

\section{Author contributions}

Therese Pross: project development, data collection and management, methodology, writing - original draft.

Maria Margarete Karsten: writing - original draft, writing review and editing.

Jens-Uwe Blohmer: supervision, validation, writing - review and editing.

Dorothee Speiser: conceptualization, writing - review and editing.

\section{Conflict of Interest}

Prof. Blohmer reports personal fees from AMGEN, AstraZeneca, Lilly, MSD, Novartis, Pfizer, Roche, SonoScape and Sysmex outside the submitted work. All other authors of this study certify that they have NO affiliations with or involvement in any organization or entity with any financial interest in the subject matter or materials discussed in this manuscript.

\section{References}

[1] Kotsopoulos ], Narod SA. Prophylactic salpingectomy for the prevention of ovarian cancer: Who should we target? Int J Cancer 2020. doi:10.1002/ijc.32916

[2] Robert Koch-Institut; Gesellschaft der epidemiologischen Krebsregister in Deutschland e.V. Krebs in Deutschland 2015/2016. Eierstockkrebs (Ovarialkarzinom) 2019. doi:10.25646/5977

[3] Rudaitis V, Mikliusas V, Januska $G$ et al. The incidence of occult ovarian neoplasia and cancer in BRCA1/2 mutation carriers after the bilateral prophylactic salpingo-oophorectomy (PBSO): A single-center prospective study. Eur J Obstet Gynecol Reprod Biol 2020; 247: 26-31. doi:10.1016/j.ejogrb.2020.01.040

[4] Zakhour M, Danovitch Y, Lester ] et al. Occult and subsequent cancer incidence following risk-reducing surgery in BRCA mutation carriers. Gynecol Oncol 2016; 143: 231-235. doi:10.1016/j.ygyno.2016.08.336

[5] Stjepanovic N, Villacampa G, Nead KT et al. Association of premenopausal risk-reducing salpingo-oophorectomy with breast cancer risk in BRCA1/2 mutation carriers: Maximising bias-reduction. Eur J Cancer 2020; 132: 53-60. doi:10.1016/j.ejca.2020.03.009

[6] Lee A, Mavaddat N, Wilcox AN et al. BOADICEA: a comprehensive breast cancer risk prediction model incorporating genetic and nongenetic risk factors. Genet Med 2019; 21: 1708-1718. doi:10.1038/s41436-0180406-9

[7] Maclnnis RJ, Knight JA, Chung WK et al. Comparing Five-Year and Lifetime Risks of Breast Cancer in the Prospective Family Study Cohort. J Natl Cancer Inst 2020. doi:10.1093/jnci/djaa178

[8] Miller H, Pipkin LS, Tung C et al. The Role of Routine Peritoneal and Omental Biopsies at Risk-Reducing Salpingo-Oophorectomy. J Minim Invasive Gynecol 2017; 24: 772-776. doi:10.1016/j.jmig.2017.03.001

[9] Kenkhuis M], de Bock GH, Elferink PO et al. Short-term surgical outcome and safety of risk reducing salpingo-oophorectomy in BRCA1/2 mutation carriers. Maturitas 2010; 66: 310-314. doi:10.1016/j.maturitas. 2010.03.018

[10] Minig L, Cabrera S, Oliver R et al. Pathology findings and clinical outcomes after risk reduction salpingo-oophorectomy in BRCA mutation carriers: a multicenter Spanish study. Clin Transl Oncol 2018; 20: 13371344. doi:10.1007/s12094-018-1865-9

[11] Rush SK, Swisher EM, Garcia RL et al. Pathologic findings and clinical outcomes in women undergoing risk-reducing surgery to prevent ovarian and fallopian tube carcinoma: A large prospective single institution experience. Gynecol Oncol 2020; 157: 514-520. doi:10.1016/j.ygyno. 2020.02.006 
[12] Weinberger V, Bednarikova M, Cibula D et al. Serous tubal intraepithelial carcinoma (STIC) - clinical impact and management. Expert Rev Anticancer Ther 2016; 16: 1311-1321. doi:10.1080/14737140.2016. 1247699

[13] Patrono MG, Iniesta MD, Malpica A et al. Clinical outcomes in patients with isolated serous tubal intraepithelial carcinoma (STIC): A comprehensive review. Gynecol Oncol 2015; 139: 568-572. doi:10.1016/ j.ygyno.2015.09.018

[14] Kyo S, Ishikawa N, Nakamura K et al. The fallopian tube as origin of ovarian cancer: Change of diagnostic and preventive strategies. Cancer Med 2020; 9: 421-431. doi:10.1002/cam4.2725

[15] Nebgen DR, Hurteau J, Holman LL et al. Bilateral salpingectomy with delayed oophorectomy for ovarian cancer risk reduction: A pilot study in women with BRCA1/2 mutations. Gynecol Oncol 2018; 150: 79-84. doi:10.1016/j.ygyno.2018.04.564

[16] De Felice F, Marchetti C, Boccia SM et al. Risk-reducing salpingo-oophorectomy in BRCA1 and BRCA2 mutated patients: An evidence-based approach on what women should know. Cancer Treat Rev 2017; 61: 1-5. doi:10.1016/j.ctrv.2017.09.005

[17] Radosa MP, Meyberg-Solomayer G, Radosa J et al. Standardised Registration of Surgical Complications in Laparoscopic-Gynaecological Therapeutic Procedures Using the Clavien-Dindo Classification. Geburtshilfe Frauenheilkd 2014; 74: 752-758. doi:10.1055/s-0034-1382925

[18] Findeklee S, Radosa JC, Schafhaupt S et al. Evaluating the use of ClavienDindo classification and Picker Patient Experience Questionnaire as quality indicators in gynecologic endoscopy. Arch Gynecol Obstet 2019; 300: 1317-1324. doi:10.1007/s00404-019-05302-w
[19] Koc N, Ayas S, Arinkan SA. Comparison of the Classical Method and SEE-FIM Protocol in Detecting Microscopic Lesions in Fallopian Tubes with Gynecological Lesions. J Pathol Transl Med 2018; 52: 21-27. doi:10.4132/jptm.2016.06.17

[20] Powell CB, Kenley E, Chen LM et al. Risk-reducing salpingo-oophorectomy in BRCA mutation carriers: role of serial sectioning in the detection of occult malignancy. J Clin Oncol 2005; 23: 127-132. doi:10.1200/jco.2005.04.109

[21] Powell CB. Risk reducing salpingo-oophorectomy for BRCA mutation carriers: twenty years later. Gynecol Oncol 2014; 132: 261-263. doi:10.1016/j.ygyno.2014.01.018

[22] Powell CB, Swisher EM, Cass I et al. Long term follow up of BRCA1 and BRCA2 mutation carriers with unsuspected neoplasia identified at risk reducing salpingo-oophorectomy. Gynecol Oncol 2013; 129: 364-371. doi:10.1016/j.ygyno.2013.01.029

[23] Piedimonte S, Frank C, Laprise C et al. Occult Tubal Carcinoma After RiskReducing Salpingo-oophorectomy: A Systematic Review. Obstet Gynecol 2020; 135: 498-508. doi:10.1097/AOG.0000000000003702

[24] Medeiros F, Muto MG, Lee $Y$ et al. The tubal fimbria is a preferred site for early adenocarcinoma in women with familial ovarian cancer syndrome. Am J Surg Pathol 2006; 30: 230-236. doi:10.1097/01.pas. 0000180854.28831 .77

[25] Walker JL, Powell CB, Chen LM et al. Society of Gynecologic Oncology recommendations for the prevention of ovarian cancer. Cancer 2015; 121: 2108-2120. doi:10.1002/cncr.29321 